\title{
An Empirical Research of Metacognitive Strategy Training and Distance Learners’ Learner Autonomy in Language Learning*
}

\author{
Wei Xu
}

Zhejiang Radio \& TV University, Hangzhou, China

\begin{abstract}
Currently, distance education features as a large number of student enrolment and person variables, which leads to the increasing pressure of distance teaching. Therefore, it is worthwhile drawing extensive attention to the distance education that transfers learning strategies correspondingly into efficient autonomous learning. So far, there are many studies on learner autonomy and metacognitive strategies training respectively, but few of them focus on the empirical study with distance education students as research subjects. The research consequently aims to find out whether metacognitive strategy training will ultimately improve learner autonomy in distance English teaching and learning, help learners increase their metacognitive awareness and benefit from taking charge of their own learning, namely, making study plans, monitoring learning process, and assessing learning effects. Consequently, it reveals that the improvement in learner autonomy is very effective to alter distance learners' existing defective learning process through metacognitive training. They learn to dominate the learning process in an active way and transfer what they have grasped to new learning materials and learning activities. Meanwhile, the research findings could be converted into practical application in distance English teaching and learning through strategy training.
\end{abstract}

Keywords: distance learners, metacognitive strategy training, learner autonomy

\section{Introduction}

\section{Distance Learners}

Distance learners are the learning subjects who are encouraged to improve the ability to continue lifelong learning even after their formal language education. Meanwhile, responsibility in learning involves distance learners in taking partial or total ownership of many traditional teacher-dominated processes, such as setting learning goals, selecting appropriate approaches and skills, monitoring the learning program, and evaluating the overall performance.

\section{Learner Autonomy}

Holec (1981) introduced the Theory of Autonomy in his book Autonomy and Foreign Language Teaching

\footnotetext{
*Acknowledgement: Thanks for the academic funds: Project of Zhejiang Provincial Philosophical and Social Science "Research on Intelligence Study for Distance English Education from the Perspective of Cognition” (Project No. 14NDJC184YB); Domestic Visitorship Programme of Colleges and Universities in Zhejiang Province "Study on MOOCs in the Distance English Education from the Perspective of Open University” (Project No. FX2015070); Higher Education Teaching Reform Project of Zhejiang Radio \& TV University “Research on English Distance Learners’ Learner Autonomy” (Project No. XJG201604); and “312” Talent Training Project of Zhejiang Radio \& TV University.

Wei Xu, M.A., associate professor, Foreign Language Department, Zhejiang Radio \& TV University.
} 
and Learning. He defined learner autonomy as "the capacity or ability to take charge of one's learning," which demonstrated in five components: setting learning goals, determining learning contents and progress, selecting appropriate approaches and skills, monitoring the program, and evaluating the overall performance. Over the last two decades, the concept of learner autonomy has gained momentum. It has been described as "buzz-word" within the context of language learning. With the focus of teaching approach transferred from teacher-centered to learner-centered, the concept of learner autonomy is beginning to enter the mainstream of language learning methodology. It is commonly agreed on the importance of helping distance learners to be more autonomous in language learning. As a matter of fact, successful distance learners are capable of dominating the learning process in an active way and being able to transfer what they have grasped to new learning materials and learning activities. They can benefit from such kind of capacity to a great degree in their lifelong education.

\section{Relationship Between Metacognitive Strategies and Learner Autonomy}

It is evidenced that there is a close relationship between metacognitive strategies and learner autonomy. First, metacognitive strategies are strong executive skills that support distance learners to be more objective-regulated. When supervising the learning process, distance learners analyze the relationship between learning objective, learning methods, and task performances. Then, they accommodate their learning process and make adjustments actively and consciously. Second, metacognitive strategies empower distance learners more responsibilities in their learning process. As the stress of language teaching and learning is transferred to be more communicative and learners' needs are oriented, distance teachers no longer behave as teaching authority and take responsibility for everything in the learning process. Instead, distance learners are encouraged to participate in the learning process in a learner-focused approach and reduce their reliance on teachers as they used to be. Integration of metacognitive strategies and autonomous learning grants learners more responsibility in language learning and enables them to study their learning needs, assess their strengths and weaknesses, and manage their language learning process. Third, metacognitive strategies help distance learners to take part in the learning process in a more active way instead of being passive recipients only.

\section{Previous Research at Home and Abroad}

The prominent role of metacognitive strategy has drawn attention of many western researchers who had strong interest in conducting metacognitive strategy training. Holec (1981) carried out metacognitive training to adult learners in a self-study center, in attempt to guide them to manage and dominate their learning process. As a consequence, the result showed that there were great changes on adult learners' learning process after training, from having no idea of how to set learning goals, make learning plans, and evaluate learning outcomes. Carrell (1989) tried to raise learners' metacogonitive awareness in an experiment of reading comprehension with the help of metacogonitive strategies as semantic mapping and experience-text-relationship. After data collection and analysis, it was evidenced that the experimental groups (EGs) made great progress in the skills of reading comprehension. As for the control groups (CGs), no improvement had been made. Therefore, Carrel (1989) got inspiring results to prove the effectiveness of metacogonitive training in improving reading comprehension of foreign language. Tabolt (1995) adopted mapping, a type of metacognitive strategy training, to the students of Hong Kong University. It was found that the trained students had more consciousness in expository writing of three styles (by using contrast method, causal analysis method, and problem solving method) and therefore gained higher scores in testing than those of the untrained students. 
Metacognitive strategy trainings provided by the foreign scholars deserve our reflection and reference. However, due to the cultural and educational differences between Chinese and foreign languages, learning strategies advocated by western scholars are not always suitable for the practice in Chinese distance English teaching. Therefore, in order to generate practical metacognitive strategy training program suitable to the learning needs of Chinese students, positive and effective strategies training forms need to be combined to agree with the actual situation of distance English curriculum reform in China.

\section{An Empirical Study}

\section{Research Questions}

What is the correlation between metacognitive strategy training and distance learners' learner autonomy? Is metacognitive strategy training helpful to improve learner autonomy?

\section{Subjects}

The subjects involved in this empirical research are 62 students of non-English majors from two classes of Zhejiang Radio \& TV University. They are freshmen with similar scores in their university entrance examination and taught by the author, an English teacher. Class 1 of 31 students serves as EG and receives college English teaching with employment of metacognitive strategy training. On the other hand, Class 2 of 31 students serves as the CG and receives routine college English teaching without metacognitive strategy.

Meanwhile, four respondents from EG and CG are chosen to have interviews before and after training. In order to guarantee that interviewees are entirely representative from different levels of respondents, the author takes the following key factors into account, such as English achievements, their involvement in questionnaires, and attitudes toward distance English teaching and learning. Precisely, the author chooses two successful students, one in EG and the other in CG, and two unsuccessful students, coming from EG and CG, respectively.

\section{Instruments}

The research makes up of both quantitative and qualitative survey. The quantitative survey refers to questionnaire on learner autonomy. While qualitative investigation includes interview. According to the data and responses collected from these instruments, the author is then able to analyze and compare the significant differences between EG and CG before and after the training.

Questionnaires. Questionnaire on learner autonomy is amended according to the literature of O’Malley and Chamot (1990), Oxford (1990), and Wen (1995). There are two parts of questionnaire. Part 1 includes background information, such as students' name, gender, and age. Part 2 consists of 26 statements about the autonomous learning in various aspects of responsibilities for one's own learning, setting learning goals, participating actively in learning, selecting appropriate learning approaches and skills, and supervising the learning process.

The items that the questionnaires indicate are of five-point Likert Scale, varying from " 1 = Never true of me;" " 2 = Not true of me;” "3 = Somewhat true of me;" " 4 = Usually true of me;” and " 5 = Always or almost true of me.” Subjects of both groups are asked to give a choice to the questions spontaneously, without hesitation.

At the end of semester, the same questionnaire is taken to subjects of both groups again, to detect whether there are differences in subjects' learner autonomy.

Interviews. Interview is regarded as a face-to-face interactive way to draw respondents' comments on the changes of autonomous learning effect before and after training. When choosing the interviewees, the author 
would take considerations into the factors, such as subjects' English achievements and their involvement in questionnaires. Precisely, two respondents are successful students with high scores, with one in EG and the other in CG. Whereas, the other two respondents are unsuccessful students with low scores, coming from EG and CG, respectively. Interviews last about 15 minutes for every interviewee and the author keeps track of the whole process of interviews.

\section{Data Collection and Analysis}

Questionnaire on learner autonomy includes subjects' background information and 26 statements about the autonomous learning in various aspects of responsibilities for one's own learning, setting learning goals, actively participating in learning, selecting appropriate learning approaches, and supervising the learning process. After the results and scores of questionnaires are collected, the author analyzes the data by Statistic Package for Social Science, Version 19.0 (SPSS 19.0) and employs descriptive statistics, namely, means, standard deviation, and paired-samples $T$ test. The standard of $t>2.000$ and $p$ (Sig.) $<0.05$ is adopted to determine significant differences between pre- and post- test of both EG and CG throughout the research. In other words, a relationship would be treated as valid in statistics on the condition that $t$-value is above 2.000. At the same time, the results are significant at the special alpha of 0.05 .

After one semester's training, the group of data would be collected again by asking respondents to finish the same questionnaires on learner autonomy. The data would be administrated again by the author to present descriptive statistics and paired-samples $T$ test and compare the differences between EG and CG. The author analyzes the responses collected from interview and communication between teacher and respondents.

\section{Metacognitive Strategy Training Program}

Raising students' awareness of metacognitive strategy. Students in distance education get used to traditional teacher-centered English teaching and learning. They depend on their teacher to a great degree and believe that teacher should take responsibility for their language learning process and language outcomes, which are on the contrary to the requirements of autonomous learning and would result in low efficiency of students' language learning. Therefore, what teacher should do at the very beginning of the training program is to make students psychologically prepared and raise their awareness of metacognitive strategy. Teacher should make students recognize the objective of metacognitive strategy training, namely, its guidance to boost distance English learning process, as well as learners' individually selected metacognitive strategies to improve distance autonomous learning, without teacher's constant guidance any more.

Questionnaires are distributed to students involved in the research, with its responses made use of to elicit a basic knowledge of students' original situations of learner autonomy and metacognitive strategy usage. Actually, appraising students' existing metacognitive capacity is treated as a crucial step in raising awareness of metacognitive strategy. It can make active students' previous knowledge and experience on metacognitive strategy. Moreover, it functions as a foundation of teacher's further tutoring as to decide what strategy should be adopted and taught during the period when students try to fulfill language activities. In addition to providing analysis and feedback for questionnaires, teacher would explicitly instruct the training program to students by organizing seminars, lectures, and interviews to illustrate the function, sequence, and importance of metacognitive strategy in foreign language learning. At the same time, students are provided with previously vivid examples of various language tasks fulfillmented by the employment of particular metacognitive strategy. In addition, teacher may elicit discussion to help students have an overall picture of metacognitive strategy. By participating 
in the instruction and discussion, students are impressed with the significance of metacognitive strategy. They would bear in mind that they could make advantages of those metacognitive strategies to facilitate their own language learning process and better fulfill their language tasks. Once they identify with the function and importance of metacognitive strategy, students would accept them enthusiastically and expect the employment of metacognitive strategy to a broader range of language tasks. On the other hand, they would also cultivate their responsibilities of independent learners and capacities of interaction to make their learning process more efficient.

In this way, students are made psychologically prepared for the metacognitive strategy training and willing to take initiatives to plan, supervise, assess the learning process, and make adjustments to their chosen strategies. Students should be capable of making study plans according to curriculum and individual needs, evaluate their advantages and disadvantages in language learning, and develop extracurricular learning resources, such as reference books, electronic periodicals, and other online materials. If students' existing learning behaviors and strategies are inappropriate to their learning, these will exert negative influences on their language learning process. Reflections on their learning process would also be urged, including motivation, attention, as well as consciousness to invest time and endeavor in it. Through those contributions, students' metacognitive strategy awareness is tremendously enhanced.

Setting goals and planning. Planning is considered as a key step in the metacognitive strategy training, which is crucial for language learning process. Therefore, teacher first gives clear instructions to the importance of setting learning goals and study plans. That is why they should adopt learning goals and plans beforehand. Having specific learning objectives may help to build up learners' motivations and strengthen their senses of responsibility to take charge of their learning. Also, it would contribute to learners' study in an orderly way, in accordance with their goals.

During this stage, some of the trained students complain that it is complicated and somewhat impractical to make plans in learning process. What is more, some of the students even have no idea of how to make study plans. As a matter of fact, it is impossible to achieve the learning objective if it occurs in a disorderly and unsystematic learning process with the lack of plans.

Next, teacher asks students to make study plans by themselves, with reference to learning objective and timetable. When plans made, considerations would be taken into such factors as requirements for the language learning, learners' actual situations, and their English performances. Then, students would be encouraged to make both long-term and short-term plans in correspondence to their language learning requirements. Short-term plan refers to those daily, weekly, and monthly requirements and expectations for their learning, while long-term plan means lasting a longer period with more difficult targets, such as passing examination as National College English Tests and improving specific English skills as listening, speaking, reading, and writing. No matter how detailed or concise the form of plan is, it should be feasible and easy to follow for students to carry out.

Table 1

Weekly Plan Sheet

\begin{tabular}{llll}
\hline Week & Learning content & Activities & Time \\
\hline 1 & Listening & - & - \\
2 & Speaking & - & - \\
3 & Reading & - & - \\
4 & Writing & - & - \\
\hline
\end{tabular}


Students are encouraged to make weekly plans (see Table 1) to make more goal-oriented practical study, which would contribute to students' sense of achievement and confidence in language learning. Feedbacks on the plan sheets would be helpful to the next two steps in metacognitive strategy training.

Monitoring. Teacher would proclaim the importance of self-monitoring to students. It is necessary for students to pay attention to the proceedings of their learning and maintain consciousness for their engagements in the learning process, to distinguish them and propel themselves toward new targets. On the contrary, it is unlikely to realize the learning target in a learning process without monitoring, for the reason that it is easy to result in randomness and laziness.

Teacher asks students to keep diaries, daily or weekly, which are beneficial for them to keep up with their schedules and introspect their learning. Keeping dairies would help students to highlight their good points, avoid shortcomings in their learning, and make adjustments accordingly.

Table 2

Monitoring Sheet

\begin{tabular}{lllll}
\hline Week & Plans finished & Strategies adopted & Strengthens & Problems \& obstacles \\
\hline 1 & - & - & - & - \\
2 & - & - & - & - \\
3 & - & - & - & - \\
4 & - & - & - & - \\
\hline
\end{tabular}

Monitoring sheets (see Table 2) are completed by students and then collected by teacher on weekend. Based on the collected information, teacher is able to determine students' progress and language outcomes, and thereafter, guide them to regulate learning plans accordingly.

Evaluating. The next stage of strategy training is to evaluate the performance of students' language learning activities, tackle problems, and make revisions when necessary. Students used to depend on external feedbacks, such as the outcomes of language tasks or testing scores to evaluate how they have learned in a certain period, which would lead to passive obedience and blindness in evaluation. Therefore, teacher should instruct students to know how to make evaluations in various aspects: Whether their learning goals are achieved; how about the plan execution; what about their adopted strategies; and what their strengthens and weaknesses are. Teacher offers help to analyze the difficulties and confusions students confronted and guide them to evaluate the overall learning process comprehensively and constantly with the purpose to determine whether students' learning objectives can be realized and try to keep track of their proceeding in a targeted way.

Table 3

Evaluating Sheet

\begin{tabular}{lllll}
\hline Item & Learning activity & \multicolumn{2}{c}{ Evaluating ranks } \\
\hline 1 & Previewing & Good & Average & Poor \\
2 & Maintaining attention during task & - & - & - \\
3 & Asking for help & - & - & - \\
4 & Target-oriented & - & - & - \\
5 & Reviewing & - & - & - \\
6 & Reflecting & - & - & - \\
\hline
\end{tabular}

Evaluation functions as a foundation of regulation and adjustment of students' language learning. By group discussion and filling in the evaluating sheet (see Table 3), students can raise their capacity of self-evaluation. 


\section{Results Analysis and Discussion}

Table 4 reveals the descriptive statistics of learner autonomy in the pre- and post- test. The total score of questionnaire on learner autonomy is 130. The maximum and the minimum of EG in the pre-test is 120 and 35 respectively, with two extremes of autonomous learning ability. At the same time, the maximum and the minimum of CG in the pre-test is 119 and 31 respectively, which indicates the distance between learners with high autonomous abilities and learners with low autonomous abilities. The mean of EG and CG in the pre-test shows that their original level of autonomous learning is very close to each other, with 72.02 of EG and 74.32 of CG. To some extent, the average score of CG is about 2 marks higher than that of EG, which indicates that subjects in CG is more capable of learner autonomy. However, things have changed in the post-test. We can see that the maximum and the minimum of EG in the post-test is 123 and 76 respectively, with tremendous improvement, especially in the minimum. The mean of EG increases largely to 92.7. In the contrast, the maximum and the minimum of CG are 109 and 34 respectively, with the mean 73.66. It almost remains as the same to the statistics in the pre-test.

Table 4

Descriptive Statistics of Pre- and Post- test About Learner Autonomy

\begin{tabular}{llllllll}
\hline & & $N$ & Score & Maximum & Minimum & Mean & Std. deviation \\
\hline \multirow{2}{*}{ Pre-test } & EG & 31 & 130 & 120 & 35 & 72.02 & 19.728 \\
& CG & 31 & 130 & 119 & 31 & 74.32 & 19.045 \\
\hline \multirow{2}{*}{ Post-test } & EG & 31 & 130 & 123 & 76 & 92.71 & 10.976 \\
& CG & 31 & 130 & 109 & 34 & 73.66 & 18.222 \\
\hline
\end{tabular}

The value of standard deviation is statistically meaningful, which draws attention. It is significantly decreased from 19.728 in the pre-test to 10.976 in the post-test in EG, but remains at the same level in CG, that is, 19.045 in the pre-test and 18.222 in the post-test. The post-test value of standard deviation in EG 10.976 indicates that responses are not far from its means. They are clustered closely. It shows that a deviation is expected in the results of this study up to 10.976 .

By taking these two groups of statistics into consideration, the author comes to the conclusion that the gap of autonomous learning ability narrows down significantly among the EG respondents and it is not so notable for the distance between two extremes of respondents who with high abilities and low abilities. On the contrary, it demonstrates that the gap of autonomous learning ability does not narrow down among the CG respondents. There is still obvious scope between two extremes of CG respondents with high autonomous abilities and low autonomous abilities.

Table 5

Paired-Samples T Test of Pre- and Post- test About Learner Autonomy

\begin{tabular}{|c|c|c|c|c|c|c|c|c|c|}
\hline & & \multicolumn{5}{|c|}{ Paired differences } & \multirow{3}{*}{$t$} & \multirow{3}{*}{ df } & \multirow{3}{*}{$\begin{array}{l}\text { Sig. } \\
\text { (2-tailed) }\end{array}$} \\
\hline & & \multirow{2}{*}{ Mean } & \multirow{2}{*}{$\begin{array}{l}\text { Std. } \\
\text { deviation }\end{array}$} & \multirow{2}{*}{$\begin{array}{l}\text { Std. error } \\
\text { mean }\end{array}$} & \multicolumn{2}{|c|}{$\begin{array}{l}\text { 95\% confidence interval of } \\
\text { the difference }\end{array}$} & & & \\
\hline & & & & & Lower & Upper & & & \\
\hline Pre-test & EG-CG & -2.306 & 24.533 & 4.406 & -11.305 & 6.693 & -0.523 & 30 & 0.605 \\
\hline Post-test & EG-CG & 19.052 & 18.942 & 3.402 & 12.104 & 26.000 & 5.600 & 30 & 0.000 \\
\hline
\end{tabular}


According to Table 5, we could analyze the paired-samples $T$ test of pre- and post- test about learner autonomy. It reveals that there is no statistically significant differences between EG and CG in the pre-test. Because $t$ value is -0.523 , lower than the critical value 2.000; and Sig. (2-tailed) value, namely $p$ value, is 0.605 , which is higher than the critical value 0.05 . However, in the post-test, we can notice remarkable difference between EG and CG. $T$ value is 5.600, exceeding the critical value 2.000, and Sig. value is 0.000 , which is much lower than the critical value 0.05 .

Table 6

Paired-Samples T Test About Learner Autonomy Between Pre- and Post- test Within EG and CG

\begin{tabular}{|c|c|c|c|c|c|c|c|c|c|}
\hline & & \multicolumn{5}{|c|}{ Paired differences } & \multirow{3}{*}{$t$} & \multirow{3}{*}{$\mathrm{df}$} & \multirow{3}{*}{$\begin{array}{l}\text { Sig. } \\
\text { (2-tailed) }\end{array}$} \\
\hline & & \multirow{2}{*}{ Mean } & \multirow{2}{*}{$\begin{array}{l}\text { Std. } \\
\text { deviation }\end{array}$} & \multirow{2}{*}{$\begin{array}{l}\text { Std. error } \\
\text { mean }\end{array}$} & \multicolumn{2}{|c|}{$\begin{array}{c}95 \% \text { confidence interval of } \\
\text { the difference }\end{array}$} & & & \\
\hline & & & & & Lower & Upper & & & \\
\hline Pair 1 & $\begin{array}{l}\text { Post-test of EG- } \\
\text { pre-test of EG }\end{array}$ & 20.691 & 11.330 & 2.035 & 16.535 & 24.847 & 10.168 & 30 & 0.000 \\
\hline Pair 2 & $\begin{array}{l}\text { Post-test of CG- } \\
\text { pre-test of CG }\end{array}$ & -0.667 & 4.592 & 0.825 & -2.351 & 1.018 & -0.808 & 30 & 0.425 \\
\hline
\end{tabular}

The author also longitudinally explores paired-sample $T$ test. The result (see Table 6) reflects that there is a remarkable difference between pre- and post-test of EG respondents, since $t$ value is 10.168, exceeding the critical value 2.000; $p$ value is 0.000 , lower than the critical value 0.05 . In contrast, the change between preand post- test of CG respondents is little, with $t$ value -0.808 , lower than the critical value 2.000 ; $p$ value 0.425 , exceeding the critical value 0.05 .

According to analysis of paired sample $T$ test calculated by SPSS 19.0, which has been under demonstration in details (see Tables 5 \& 6), it reveals that $p$ value of learner autonomy of both EG and CG in the pre-test is higher than 0.05 . Therefore, it is no significant difference between EG and CG before the training, which is treated as solid foundation and prerequisite of test and comparison of the two groups involved in this research. After the training program, $T$ test results show that $p$ value of learner autonomy of both EG and CG in the post-test is below 0.05, which means significant differences between EG and CG. Extraordinary progress is witnessed in EG with the average score rising from 72.02 in the pre-test to 92.71 in the post-test. However, no improvement has been made in CG.

By summarizing what the respondents say in interview, the author finds out that successful learners have recognized the importance of learning English. Meanwhile, they show interest in English and would invest both time and effort in English relevant exercises and entertainments after class to improve their English skills. They prefer student-focused teaching to teacher-centered approach. That is to say, they do not take teacher as the authority in class and would take charge of the learning process by setting learning objectives, choosing learning contents, and accomplish language tasks after class. Sometimes, they would adopt learning strategies to enhance their English learning unconsciously.

Obviously, the training has an impact on respondents of EG in the aspect of learner autonomy. The metacognitive strategy training broadens their horizons and helps them to get rid of original inappropriate learning methods. It inspires them to have cognitions of their own learning states and then adopt suitable learning strategies accordingly, rather than imitate others' strategy mechanically. What is more, metacognitive strategy is effective to overcome their frustrations and anxiety when in difficulty, and helps to rebuild their confidence in English learning. 


\section{Conclusion}

Based on the above quantitative and qualitative analysis, an apparent conclusion can be made that metacognitive strategy training effectively enhances distance learners' autonomous learning ability. They improve their abilities in setting learning objectives, determining learning contents and progress, selecting appropriate approaches and skills, monitoring the program, and evaluating the overall performance. Gradually, they learn to dominate the learning process in an active way and transfer what they have grasped to new learning materials and learning activities. Then, they accommodate their learning activities and make adjustments actively and consciously. They manage their schedules under control, knowing what they have already mastered, what they have not, how to learn effectively, and ultimately, turn to be the masters of their own learning process, rather than only teacher's arrangements followers. Hence, it would be rewarded in the distance education that transfers metacognitive strategy into efficient autonomous learning, which identifies with the purpose of this research.

As for pedagogical implications, it is advised to establish learning support service on the basis of learners' autonomous learning. In that case, distance learners can realize extensive online courses, such as MOOCs and microcourses, which enjoy such popularity nowadays. Further study can be made to evaluate strengths and weaknesses of the integration of metacognitive strategy and learner autonomy in distance education. As a consequent, a greater resonance and effect of distance autonomous learning, which is propelled by metacognitive strategy, can be generated to advance teaching reform and effectiveness.

\section{References}

Carrell, P. L. (1989). Metacognitive awareness and second language reading. TESOL Quarterly, 73, 121-134.

Cotterall, S. (1995). Readiness for autonomy: Investigating learner belief. System, 23(2), 195-205.

Dickinson, L. (1993). Talking shop: Aspects of autonomous learning. ELT Journal, 47(4), 330-335.

Holec, H. (1981). Autonomy and foreign language learning. Oxford, U.K.: Pergamon Press.

Little, D. (1990). Learner autonomy in practice. In Autonomy in language learning (pp. 7-15). London, U.K.: CILT.

Littlewood, W. (1999). Defining and developing autonomy in East Asian contexts. Applied Linguistics, 20(1), 71-94.

O’Malley, J. M., \& Chamot, A. U. (1990). Learning strategies in second language acquisition. Cambridge, U.K.: Cambridge University Press.

Oxford, R. L. (1990). Language learning strategies: What every teacher should know. Rowley, Mass: Newbury House.

Tabolt, D. (1995). Metacongitive strategy training for reading: Developing second language learners' awareness of expository that patters (Unpublished Ph.D. dissertation, Hong Kong University).

Tan, J. D. (2012). Research on self-regulated learning activities in virtual learning community: Meta-cognitive perspective. Modern Educational Technology, 16(11), 107-110.

Xu, W. (2013). Conceptual learning for distance English based on cloud service. Modern Educational Technology, 23(12), 44-48.

$\mathrm{Xu}, \mathrm{W}$. (2014). Intelligence study of distance English based on learning cell and metacognition. Journal of Distance Education, 32(3), 84-90.

$\mathrm{Xu}, \mathrm{W}$. (2015). Research of MOOCs in the distance English education from the perspective of U-learning. China Adult Education, 368(7), 126-130.

Wenden, A. L. (1987). Meta-cognition: An expanded view of the cognitive abilities of L2 learners. Language Learning, 16(37), 573-596.

Wen, Q. F. (1995). Differences in methods between successful and unsuccessful English learners. Foreign Language Teaching and Research, 6(3), 61-66. 